\title{
Utilization of Cervical Cancer Screening Service Among Nurses in Ekiti State, Nigeria
}

\author{
Babajide Augustine Owolabi $^{1}$, Prisca Olabisi Adejumo ${ }^{2}$ \\ ${ }^{1}$ School of Midwifery, Ado Ekiti, Nigeria \\ ${ }^{2}$ Department of Nursing, University of Ibadan, Ibadan, Nigeria
}

Email address:

owolabijide007@gmail.com (B. A. Owolabi), bisiandbayo@yahoo.com (P. O. Adejumo)

*Corresponding author

\section{To cite this article:}

Babajide Augustine Owolabi, Prisca Olabisi Adejumo. Utilization of Cervical Cancer Screening Service Among Nurses in Ekiti State, Nigeria. Cancer Research Journal. Vol. 9, No. 1, 2021, pp. 71-78. doi: 10.11648/j.crj.20210901.19

Received: February 17, 2021; Accepted: March 9, 2021; Published: March 17, 2021

\begin{abstract}
Cervical cancer is a preventable cause of death among women especially in developing nations which can be prevented through regular and timely screening. Nurses who are assume to be knowledgeable about cervical cancer screening options and ought to act as leading examples in utilization of cervical cancer screening services, however studies have documented otherwise, The purpose of this study therefore, is to evaluate the Utilization of Cervical Cancer Screening Service among Nurses in Ekiti State, as little literary study have been done on the topic among nurses in the setting. A mixed method design study was conducted in four health facilities that were purposively selected in Ekiti State, Nigeria. A total of 278 consenting nurses participated in the study. Data were collected using self- structured questionnaire and interview guide. Data were analyzed using chi square and Student's t-test at $p=0.05$. Nurses' mean age was 35 years with average work experience of 10 years. Results from the study shows that a preponderance of the nurses which stood at $75.8 \%$ had never been screened for cervical cancer while only 24.2 have been screened and $90.6 \%$ willing to be screened if given the opportunity. It was observed that Nurses' avoid cervical screening exercise as a result of the following; lack of time, fear of positive result, embarrassment of exposing the vulva to the opposite sex, cost implication and spiritual assurance that they can never be a victim of cervical cancer. Also 164 (59.2\%) of the participants had adequate knowledge about cervical cancer screening, while slightly more than half $143(51.6 \%)$ of the respondent had positive attitude towards cervical cancer screening, There was also a significant association between years of professional practice and utilization of cervical cancer screening service as $p$ value was 0.003 This implies that participants who had longer years of professional experience are more likely to utilize cervical cancer screening services than those who had shorter years of professional experience. Therefore, the null-hypothesis was rejected. it was also noted that participants' level of academic education did not determine whether or not their attitude was positive or negative as the $\mathrm{p}$ value gotten was 0.544 The null-hypothesis was not rejected. It was concluded that nurse's utilisation rate was very low. Thus, regular educational programs on cervical cancer, government and hospital management should make policies that will encourage utilization of cervical cancer screening among nurses are recommended.
\end{abstract}

Keywords: Utilization, Cervical Cancer Screening, Nurses, Ekiti State

\section{Introduction}

Globally, Cervical cancer is the $4^{\text {th }}$ commonly occurring cancer in women and the $8^{\text {th }}$ most commonly occurring cancer overall, with over 500,000 new cases in 2018 and the most common cancer in women in Eastern and Middle Africa. With majority $(85 \%)$ of the global burden occurring in the less developed regions, where it accounts for almost $12 \%$ of all occurring female cancers. [1, 2] In Africa, approximately 6,000 women die of this preventable disease each year [3]. Also Also Ndejjo, Mukama, Musabyimana and Musoke [4] revealed that only $4.8 \%$ of 900 Uganda women had been screened for cervical cancer while $48.8 \%$ of them did it on health care workers' request.

Cervical cancer was reported to be the second most frequent cancer among women in Nigeria [5]. In south-western Nigeria, data retrieved from the Ife-Ijesa Cancer Registry between the 
period 2010-2014 identified that out of the 2,042 total cases registered, the relative distribution of cancers at Reproductive sites was $18 \%$ with cervical cancer constituting more than half (55\%). This agrees with Ojo, Adeola, Awe, Oluwasina, Akinyemi, Omotoso, \& Alatise, in data retrieved from the Cancer Registry of the Federal Medical Centre, Ido Ekiti between 2010-2015 which also reveals that the commonest site of infection is the breast (29.9\%) followed by the cervix (17.5\%). [6]. Despite this hike, Babatunde, Elegbede, Ayodele, \& Abidoye reported a low uptake of cervical screening service among women in Ikere Ekiti local government of Ekiti State. [7]

About 50.33 million Nigeria women aged 15 years and above who are at risk of developing cervical cancer. Further estimates indicate that every year 14,089 women are diagnosed with cervical cancer and more than half, over 8,240 die from this preventable disease. [5].

Cervical cancer is a preventable disease due to the long pre invasive stage. Early detection and appropriate treatment are possible if robust screening is implemented. Also early cervical epithelial changes can be identified by a Pap smear test, which is the primary screening test for detection of precancerous cervical intraepithelial neoplasia and the early stage of invasive cervical cancer [8].

Therefore, early detection of the presence of pre-cancerous stage through timely screening has been indicated in inhibiting the progression of many forms of tumors into malignant stages [9] cervical cancer screening has been found to reduce the incidence of cervical cancer and associated death. In England, screening currently prevents $70 \%$ of cervical cancer deaths and if everyone attended screening regularly, $83 \%$ could be prevented. [10].

Regardless of the rise in the prevalence of cervical cancer, its associated deaths and increasing efforts towards awareness and education about the importance of regular cervical cancer screening, studies have shown a very low level of utilization of cervical cancer screening service even among female health care workers Arulogun \& Maxwell; Bakari, Takai \& Bukar, Report $23.3 \%$ and $32.6 \%$ uptake of cervical screening services among female nurses in Maiduguri and Ibadan respectively. [11, 12]

Health care workers (HCW) especially nurses are always looked upon as "role models" in health related issues. As they play major role in health education of the public on the availability and need for cervical cancer screening services and immunization. [13] Report in a study among Ekiti women shows that majority $71.8 \%$ of the participants got to know about cervical cancer and its screening through Nurses. Nurses who are informed individuals are expected to have more information and knowledge about several health related services and also act as leading examples in the utilization of cervical cancer screening service, but studies have documented otherwise $[14,15,16]$. Despite the high level of knowledge about cervical cancer screening and its benefit, nurses have been reported to show very low utilization and uptake of cervical cancer screening service [11, 14] with varying statistics among female nurses and other female Health care workers. Thus poses a greater threat to health care delivery system in Nigeria hence, prompt action must be taken to address this persistent trend in Nigeria. Although cervical cancer seems to be over flogged in some settings but very little work has been done on utilization, attitude and perception of cervical cancer screening among nurses especially in Ekiti State. Due to the peculiarity of the state, thus, this study was set to assess the utilization of cervical cancer screening service among nurses in Ekiti State, Nigeria

\section{Research Questions}

The following research question and hypothesis guide the study

1. What is the level of knowledge among nurses on cervical cancer screening in Ekiti State, Nigeria?

2. What is the attitude of nurses towards cervical cancer screening in Ekiti State, Nigeria?

3. What is the level of utilization of cervical cancer screening Service among the nurses in Ekiti State, Nigeria?

4. What are the factors influencing utilization of Cervical Cancer screening Service as identified by nurses in Ekiti State, Nigeria?

Research hypothesis

HO 1: There is no significant difference between highest level of qualifications of the respondents and attitudes toward utilization of cervical cancer screening.

H0 2: There is significant association between years of professional practice and utilization of cervical cancer screening service

\section{Methodology}

Purposive sampling techniques were use in selecting the four hospitals 2 teaching hospital, 1 general hospital and 1 state specialist hospital, because they provide mainly secondary and tertiary health care services with highest number of registered nurses, high patronage from within and outside Ekiti state and each hospital has facilities for cervical cancer screening and also houses Cancer Registries.

Proportionate technique was use in the distribution of respondents to each hospital based on the nurses' population in each hospital.

Systematic sampling techniques was used in selecting nurses in the different hospitals from the list on the duty roaster in each unit of the hospital with interval of 2 , calculated using the ratio of the total population with calculated sample size $668 / 278=2.4=2$.

Purposive sampling techniques was used in selecting the head of unit in each of the units of the hospitals for the Key informant interview since they are informed individuals, unit head and are involved in decision making committee of the hospitals. It was assumed they have more information on factors influencing utilization in their respective hospitals.

\section{Result}

\subsection{Socio-demographic Characteristics of Respondents}

Table 1 below shows the respondents'socio-demographic 
characteristics of respondents. Results from the study indicate that the greatest proportion of the respondents, $72.2 \%$ were aged between 20-39 years, $71.8 \%$ were divorced/separated and $92.4 \%$ were Christians. More so, $54.9 \%$ had first degree as their highest level of education, $93.9 \%$ had 1-20 years of experience and $53.1 \%$ pay out of pocket for healthcare.

\subsection{Knowledge of Respondents on Cervical Screening}

Results from the study show that $96.4 \%$ of them know that human papilloma virus can cause cervical cancer, $91.3 \%$ know that vaccination against human papilloma virus infection will prevent development of cervical cancer, $97.1 \%$ believe that early detection and treatment of cervical cancer through VIA/ pap smear screening can prevent development of cervical cancer, while $95.3 \%$ know that mortality rate of cervical cancer can be reduced by early detection through screening. Also, 78.8\% know centres where cervical screening is being performed in Ekiti State, Nigeria. However, 28.5\% do not know that HPV DNA testing is one of the methods used in cervical cancer screening service and $23.8 \%$ do not know that the risk of cervical cancer increases with age and $32.9 \%$ do not know that cigarette smoking and alcohol intake can increase ones' chance of developing cervical cancer. In addition, 94.2\% have heard of human papilloma virus before, while $87.7 \%$ know it is the main cause of cervical cancer.
Table 1. Socio-demographic Characteristics of Respondents.

\begin{tabular}{lll}
\hline Socio-demographic Characteristics & Frequency & Percent (\%) \\
\hline Age Range & & \\
20 - 39 years & 200 & 72.2 \\
40 - 59 years & 77 & 27.8 \\
Marital status & & \\
Married & 74 & 26.7 \\
Divorced/Separated & 199 & 71.8 \\
Widowed & 4 & 1.4 \\
Religion affiliation & & \\
Christianity & 256 & 92.4 \\
Islam & 21 & 7.6 \\
Highest level of education & & \\
Diploma & 115 & 41.5 \\
First degree & 152 & 54.9 \\
M.Sc. & 9 & 3.2 \\
PhD and above & 1 & 0.4 \\
Years of professional practice & & \\
1 - 20 years & 260 & 93.9 \\
21 - 40 years & 17 & 6.1 \\
Financial source of healthcare & & \\
NHIS & 108 & 39 \\
Out of pocket & 147 & 53.1 \\
Other & 22 & 7.9 \\
\hline
\end{tabular}

Mean Age - 35; Mean Year of Practice - 10

Table 2. Knowledge of Cervical Cancer Screening.

\begin{tabular}{|c|c|c|c|c|}
\hline \multirow{2}{*}{ Knowledge of Cervical Cancer Screening } & \multicolumn{2}{|c|}{ Incorrect } & \multicolumn{2}{|c|}{ Correct } \\
\hline & Freq. & $\%$ & Freq. & $\%$ \\
\hline Human papilloma virus can cause cervical cancer? & 10 & 3.6 & 267 & 96.4 \\
\hline Vaccination against human papilloma virus infection will prevent development of cervical cancer? & 24 & 8.7 & 253 & 91.3 \\
\hline $\begin{array}{l}\text { Early detection and treatment of cervical cancer through VIA/ pap smear screening can prevent development of } \\
\text { cervical cancer? }\end{array}$ & 8 & 2.9 & 269 & 97.1 \\
\hline Mortality rate of cervical cancer can be reduced by early detection through screening? & 13 & 4.7 & 264 & 95.3 \\
\hline Do you know any centre where cervical screening is been performed in Ekiti State, Nigeria? & 59 & 21.3 & 218 & 78.7 \\
\hline Do you know where cervical screening is been performed in hospital where you work? & 77 & 27.8 & 200 & 72.2 \\
\hline Do you know that HPV DNA testing is one of the methods used in cervical cancer screening service? & 79 & 28.5 & 198 & 71.5 \\
\hline HPV can be cure if detected early? & 28 & 10.1 & 249 & 89.9 \\
\hline The risk of cervical cancer increases with Age? & 66 & 23.8 & 211 & 76.2 \\
\hline A positive family history increase ones chance of developing cervical cancer? & 52 & 18.8 & 225 & 81.2 \\
\hline Cigarette smoking and alcohol intake can increase ones chance of developing cervical cancer? & 91 & 32.9 & 186 & 67.1 \\
\hline Having multiple sexual partners increase the chance of cervical cancer? & 22 & 7.9 & 255 & 92.1 \\
\hline Late menopause after the age of 55yrs is a risk of developing cervical cancer & 156 & 56.3 & 121 & 43.7 \\
\hline Use of contraceptive is risk factor for developing cervical cancer & 117 & 42.2 & 160 & 57.8 \\
\hline Breast feeding is also a risk factor for developing cervical cancer? & 233 & 84.1 & 44 & 15.9 \\
\hline Early exposure to sexual intercourse is a risk factor for developing cervical cancer? & 59 & 21.3 & 218 & 78.7 \\
\hline Do you know you can be infected by human papilloma virus? & 92 & 33.2 & 185 & 66.8 \\
\hline HIV is the main cause of cervical cancer? & 233 & 84.1 & 44 & 15.9 \\
\hline Have you heard of human papilloma virus before? & 16 & 5.8 & 261 & 94.2 \\
\hline Human papilloma virus is the main cause of cervical cancer? & 34 & 12.3 & 243 & 87.7 \\
\hline
\end{tabular}

Table 3 below shows level of knowledge of cervical cancer screening. Results from the study indicate that the greatest percentage of the participants, $164(59.2 \%)$ had adequate knowledge about cervical cancer screening, having get more than $9(50 \%)$ of the knowledge base question with 113 $(40.8 \%)$ having inadequate knowledge about cervical cancer screening, having score less than $9(50 \%)$ of the knowledge base question
Table 3. Level of knowledge of cervical cancer screening.

\begin{tabular}{lll}
\hline Level of Knowledge & Frequency & Percent (\%) \\
\hline Inadequate Knowledge & 113 & 40.8 \\
Adequate Knowledge & 164 & 59.2 \\
Total & 277 & 100 \\
\hline
\end{tabular}

Level of Knowledge

Attitude of Respondents towards Cervical Cancer Screening 
Table 4 shows attitude of respondents towards cervical cancer screening. Results from the study indicates that $27.8 \%$ are scared of going for cervical cancer screening because it is painful, while $45.1 \%$ stated they know it is necessary but it has not occurred to them to go for it. Also, $36.8 \%$ disagreed with the fact that there is no need for screening since both partners are faithful to each other, while $34.7 \%$ disagreed with the fact that there is no need for the test since they are not at risk of developing cervical cancer. Also, 31\% disagreed with the fact that time is a factor militating against cervical cancer screening. However, $30 \%$ disagreed with testing stating that it is embarrassing to expose themselves to doctors when they are not at risk of contracting cervical cancer. In addition, 36.8\% agreed that they will screen for cervical cancer in the future.

Table 4. Attitude of Respondents towards Cervical Cancer Screening.

\begin{tabular}{|c|c|c|c|c|c|c|c|c|c|c|}
\hline \multirow{2}{*}{ Statement Items } & \multicolumn{2}{|l|}{ SA } & \multicolumn{2}{|l|}{$\mathbf{A}$} & \multicolumn{2}{|l|}{$\mathbf{U}$} & \multicolumn{2}{|l|}{ D } & \multicolumn{2}{|l|}{ SD } \\
\hline & Freq. & $\%$ & Freq. & $\%$ & Freq. & $\%$ & Freq. & $\%$ & Freq. & $\%$ \\
\hline I am scared of going for cervical cancer screening because is painful & 48 & 17.3 & 77 & 27.8 & 32 & 11.6 & 74 & 26.7 & 46 & 16.6 \\
\hline $\begin{array}{l}\text { I don't really need cervical cancer screening because my partner and I are faithful to } \\
\text { each other }\end{array}$ & 23 & 8.3 & 58 & 20.9 & 22 & 7.9 & 102 & 36.8 & 72 & 26 \\
\hline I don't really need it because I am not at risk of developing cervical cancer & 32 & 11.6 & 47 & 17 & 14 & 5.1 & 96 & 34.7 & 88 & 31.8 \\
\hline I know is necessary but it has not occurred to me to go for it & 41 & 14.8 & 125 & 45.1 & 30 & 10.8 & 56 & 20.2 & 25 & 9 \\
\hline I don't really know where the screening it performed in Ekiti & 37 & 13.4 & 52 & 18.8 & 10 & 3.6 & 80 & 28.9 & 98 & 35.4 \\
\hline I don't have time for the screening & 20 & 7.2 & 75 & 27.1 & 32 & 11.6 & 86 & 31 & 64 & 23.1 \\
\hline $\begin{array}{l}\text { I like to do it but will prefer to have it done in a private hospital rather than where I } \\
\text { work }\end{array}$ & 52 & 18.8 & 80 & 28.9 & 80 & 28.9 & 71 & 25.6 & 52 & 18.8 \\
\hline It is embarrassing to expose myself to doctors when am not at risk & 44 & 15.9 & 57 & 20.6 & 27 & 9.7 & 83 & 30 & 66 & 23.8 \\
\hline I will screen for cervical cancer in future & 60 & 21.7 & 102 & 36.8 & 34 & 12.3 & 43 & 15.5 & 38 & 13.7 \\
\hline I have never recommended cervical cancer screening for someone before & 30 & 10.8 & 106 & 38.3 & 16 & 5.8 & 60 & 21.7 & 65 & 23.5 \\
\hline I believe God cannot allow me to develop cervical cancer hence, I don't really need it & 44 & 15.9 & 68 & 24.5 & 30 & 10.8 & 64 & 23.1 & 71 & 25.6 \\
\hline
\end{tabular}

Table 5 shows types of attitude displayed by participants. Results from the study indicates that slightly more than half $143(51.6 \%)$ of the respondents had positive attitude towards cervical cancer screening. having get more than $5(50 \%)$ of the attitude base question right and 134 (48.4\%) negative attitude toward cervical cancer screening, having score less than $5(50 \%)$ of the attitude base question

Table 5. Types of Attitude Displayed by Participants.

\begin{tabular}{lll}
\hline Attitude Types & Frequency & Percent\% \\
\hline Negative Attitude & 134 & 48.4 \\
Positive Attitude & 143 & 51.6 \\
Total & 277 & 100 \\
\hline
\end{tabular}

Pattern of Cervical Cancer Screening

Table 6 shows Pattern of Cervical Cancer Screening. Results from the study show that the greatest proportion of the respondents, $75.8 \%$ had never been screened for cervical cancer. The reasons given for non-use of screening services include lack of time, $38.6 \%$, fear of result, $32.5 \%$, embarrassment/cost consideration, $19.1 \%$

Table 6. Pattern of Cervical Cancer Screening.

\begin{tabular}{lll}
\hline Screening for Cervical cancer & Frequency & Percent (\%) \\
\hline $\begin{array}{l}\text { Never screened } \\
\text { Screened }\end{array}$ & 210 & 75.8 \\
Regularity of Screening & 67 & 24.2 \\
Every year & 16 & 5.8 \\
Every 2 year & 12 & 4.3 \\
Every 3 year & 18 & 6.5 \\
Every 4 year & 21 & 7.6 \\
Never screened & 210 & 75.8 \\
Reasons for non-use of Screening Services & & \\
Lack of time & 107 & 38.6 \\
No approval from my spouse & 27 & 9.7 \\
Embarrassment/cost consideration & 53 & 19.1 \\
Fear of result & 90 & 32.5 \\
\hline
\end{tabular}

\section{Reasons for not Using Cervical Screening Services}

Table 7 shows the reasons for not using cervical screening services. Results from the study indicates that the most implicated reason for non-use of cervical cancer screening services is fear of the result, $31 \%$

Table 7. Reasons for not using Cervical Screening Services.

\begin{tabular}{lll}
\hline Reasons & Frequency & Percent (\%) \\
\hline Fear of result & 86 & 31 \\
Expensive & 6 & 2.2 \\
Not interested & 3 & 1.1 \\
Not yet ready & 3 & 1.1 \\
Painful & 5 & 1.8 \\
Not at risk & 31 & 11.2 \\
Lack of time & 11 & 4 \\
Religious faith & 132 & 47.7 \\
Total & 277 & 100 \\
\hline
\end{tabular}

\section{Hypotheses testing}

H0 1: There is no significant difference between highest level of qualifications of the respondents and attitudes toward utilization of cervical cancer screening.

Table 8. Association between highest level of Education and attitude towards cervical cancer screening.

\begin{tabular}{lllllll}
\hline $\begin{array}{l}\text { Highest level of } \\
\text { education }\end{array}$ & \multicolumn{2}{l}{ Displayed Attitude } & Chi-sq. & df & p & Remark \\
\hline \multirow{2}{*}{ Diploma } & Negative & Positive & & & & \\
& 53 & 62 & & & & \\
& $(39.6 \%)$ & $(43.4 \%)$ & 0.412 & 1 & 0.544 & NS \\
University Degree & 81 & 81 & & & & \\
& $(60.4 \%)$ & $(56.6 \%)$ & & & & \\
\hline
\end{tabular}

Table 8 shows the no significant association between the level of education and attitude towards the screening service is 0.544 which is more than $0.05(\mathrm{p}>0.05)$. This implies that participants' level of academic education did not determine whether or not their attitude would be positive or negative 
towards the screening services. Therefore, the nullhypothesis was not rejected.

H0 2: There is significant association between years of professional practice and utilization of cervical cancer screening service

Table 9 shows the significant association between years of professional practice and utilization of cervical cancer screening service is 0.003 which is less than $0.05(\mathrm{p}<0.05)$. This implies that participants who had longer years of professional experience are more likely to utilize cervical cancer screening services than those who had shorter years of professional experience. Therefore, the null-hypothesis was rejected.

Table 9. Association between years of professional practice and utilization of cervical cancer screening service.

\begin{tabular}{llllll}
\hline Years of professional practice & Screening Status & & Chi-sq. & df & p \\
\hline \multirow{3}{*}{$1-20$ years } & Not Screened & Screened & & & \\
& 206 & 54 & 9.399 & 1 & \\
$21-40$ years & $(96.3 \%)$ & $(85.7 \%)$ & & & \\
& 8 & $(14.3 \%)$ & & \\
\hline
\end{tabular}

\section{Discussion of Findings}

\subsection{Socio Demographic Characteristics of the Respondents}

Results of the study indicate that the greatest proportion of the respondents, $72.2 \%$ were aged between $20-39$ years, $71.8 \%$ were divorced/separated and $92.4 \%$ were Christians. More so, $54.9 \%$ had first degree as their highest level of education, $93.9 \%$ had 1-20 years. This agrees with Ifemelumma, Anikwe, Okorochukwu, Onu, Obuna, Ejikeme \& Ezeonu in their study shows that majority of the respondents, $179(46.1 \%)$, were between 21 and 30 years of age and 209 (53.9\%) Of the respondents were married, while $41.2 \%$ were single. Nurses with less than 5 years of working experience made up the largest proportion (47.2\%). [17]. Also Yörük, Selda, Açıkgöz, Ayla, Türkmen, Hülya, \& Ergör, in their study among 367 female health care workers shows that the mean age of the respondents was 28.2 years with more than half, $196(53.3 \%)$ of them been of the protestant religion. One hundred and eighty-one $(49.3 \%)$ of them were married and $304(82.8 \%)$ of the respondents had a diploma and working experience of 1-5 years respectively. [18]

\subsection{Knowledge of the Respondents on Cervical Cancer and Its Screening Service}

Results from this study also shows that $96.4 \%$ of the respondents know that Human Papilloma Virus can cause cervical cancer, $91.3 \%$ know that vaccination against Human Papilloma Virus infection will prevent development of cervical cancer, $78.8 \%$ of the respondents know centres where cervical cancer screening is being performed in Ekiti State. However, $28.5 \%$ do not know that HPV DNA testing is one of the methods used in cervical cancer screening service and $23.8 \%$ do not know that the risk of cervical cancer increases with age and $32.9 \%$ do not know that cigarette smoking and alcohol intake can increase ones' chance of developing cervical cancer. In addition, $94.2 \%$ have heard of human papilloma virus before, thus more than half of the participants, $59.2 \%$ had adequate knowledge about cervical cancer screening. This agrees with the in LUTH, majority of the nurses, $92 \%$ of the respondents were aware of the causative organism of cervical cancer (human papilloma virus). $99 \%$ of the nurses have good knowledge of cervical cancer screening. Also $97.1 \%$ believe that early detection and treatment of cervical cancer through VIA/pap smear screening can prevent development of cervical cancer, while 95.3\% know that mortality rate of cervical cancer can be reduced by early detection through screening [15] It also corroborates with study on perception and utilization of cervical cancer screening among female nurses in University College Hospital, Ibadan, Nigeria Which reveals that more than half of the nurses $54.5 \%$ correctly identified HPV as the primary cause of cervical cancer, the overall analysis of knowledge of respondents showed that $84.9 \%$ had average knowledge score, $14.3 \%$ had poor knowledge.[11] It also agrees with another study among female health care providers which reveals that $100 \%$ of Health care providers were aware of cervical cancer. [19] Also Also Yörük, Selda, Açıkgöz, Ayla, Türkmen, Hülya, \& Ergör, Gül [18] shows $(86.9 \%)$ health workers had a good level of knowledge on cervical cancer. Most of the respondents, 341 (92.9\%), had heard about cervical cancer. Similarly, 299 (81.5\%) and 140 $(38.1 \%)$ of them knew that cervical cancer was preventable and were aware of its preventive measures, respectively. Also $223(60.8 \%)$ and $133(36.2 \%)$ of respondents knew that early screening and vaccination for HPV could prevent cervical cancer, while $291(79.3 \%)$ and $271(73.8 \%)$ of stated using holy water and praying to God as the preventive measures. Also $183(37.6 \%)$ mentioned visual inspection with acetic acid as a screening method. Similarly, 113 (30.8\%) mentioned Pap smear as a screening method. Majority of the respondents, $306(83.4 \%)$, knew that the cervical cancer screening test was used to check the health of the cells of the cervix. Regarding the cervical cancer screening services, 158 $(43.1 \%)$ of the respondents stated that there was no cervical cancer screening test in their institution.

This suggests that nurses in Ekiti like other nurses globally have registered nursing certificates as the least requirement to practice, they have sufficient knowledge on cervical cancer and cervical cancer screening from their nursing schools as a greater percentage of then know the causative organism, vaccine available and types of screening for early detection of cervical cancer. 


\subsection{Pattern of Cervical Cancer Screening Service Utilization among Respondents}

Results from the study show that the greatest proportion of the respondents, $75.8 \%$ had never been screened for cervical cancer and out of the $24.2 \%$ who have done it, $37.2 \%$ had only been screened once and $45.8 \%$ of them between the age of $36-45$ as at last screening with $90.6 \%$ willing to be screened if given the opportunity. The reasons given for nonusage of screening services include lack of time (38.6\%), fear of result $(32.5 \%)$, embarrassment/cost consideration (19.1\%), this corroborates with Awodele, Adeyomoye, Awodele, Fayankinnu,\& Dolapo, in their study which shows that minority $32.6 \%$ had never used cervical cancer screening facility and main reasons for non-usage included lack of time $(50.8 \%)$, fear of result (13.9\%) and not being sexually active $(6.3 \%)$. [15] This also agrees with the study on utilization of cervical cancer screening among female nurses in University College Hospital, Ibadan, Nigeria which reveals that minority (34.6\%) of the nurses had made use of cervical cancer screening and main reason cited by this set of nurses were lack of time, fear of the result, cumbersome procedure, cost consideration, and not being sexually active. [11] Also Fasanu, Akindele, Adebimpe, Ala, Omopariola \& Adisa, in their study among health care workers in Maiduguri which revealed that majority of the nurses (141) were aware of Pap smear and only minority constituting $23.3 \%$ of the respondents had previously done the test with majority of the women willing to do the test if offered the opportunity either free $(70.6 \%)$ or with payment $(29.4 \%)$.[20] This is in consonance with another study among female health care providers which reveals that minority (18.4\%) of the respondents have never undergone cervical cancer screening.[19] Also Yörük, Selda, Açıkgöz, Ayla, Türkmen, Hülya, \& Ergör, Gül in Ethiopia shows that majority of the nurses in their study, $325(88.6 \%)$ have not been screened for cervical cancer before. And among the few (11.4\%) who were screened for cervical cancer, acetic acid test accounted for $18(42.8 \%)$. fear of the result and lack of sufficient information among others constituted a significant percentage for reason for non utilization. One hundred and eighty $(49.1 \%)$ of the respondents stated that no vaccination for HPV was available in their institution, and all study respondents were not vaccinated. [18]

\subsection{Attitude of the Respondent on Cervical Cancer and Screening Service}

Results from the study indicates that $27.8 \%$ of the participants were scared of going for cervical cancer screening because it is painful, while $45.1 \%$ stated they know it is necessary but it has not occurred to them to go for it. Also, 36.8\% disagreed with the fact that there is no need for screening since both partners are faithful to each other, while $34.7 \%$ disagreed with the fact that there is no need for the test since they are not at risk of developing cervical cancer. Also, 31\% disagreed with the fact that time is a factor militating against cervical cancer screening. However, 30\% disagreed with testing stating that it is embarrassing to expose themselves to doctors when they are not at risk of contracting cervical cancer. In addition, $36.8 \%$ agreed that they will screen for cervical cancer in the future. This agrees with Awodele, Adeyomoye, Awodele, Fayankinnu, \& Dolapo [15], in their study carried out among female nurses in University Teaching Hospital Lagos which shows good number of the nurses (88\%) correctly perceived cervical cancer to be preventable and $82.0 \%$ believed that screening should be carried out as soon as sexual intercourse starts irrespective of age. It also correlates with Fasanu, Akindele, Adebimpe, Ala, Omopariola, \& Adisa in their study which shows majority $146(60.8 \%)$ of the respondents felt that early detection has good treatment outcome.[20] However, it disagrees with the study conducted on attitude and practice of cervical cancer screening among female health workers in university of Port Harcourt teaching hospital, Rivers State which shows that a good number of the respondents 323 $(91.7 \%)$ did not support opinion that all women of child bearing age should participate in the uptake of cervical cancer screening, while a few $29(8.3 \%)$ supported it. Majority of the health workers $326(92.6 \%)$ did not support that cervical cancer screening should be for only those in $\mathrm{O}$ \& G unit while 26 (7.3\%) support it. 325 (92.3\%) of respondents from the same study disagree with the opinion that cervical cancer screening should form part of the routine examination for women of menopausal and child bearing age, only a few $27(7.6 \%)$ agreed. $48(13.7 \%)$ of the respondents agree that women who maintain good genital hygiene and one sex partner do not need cervical cancer screening while $304(86.3 \%)$ disagreed. The result however showed that the attitude of female health workers towards the uptake of cervical cancer screening was negative and not favorable. Similarly, it was reported from the study that only 93 (26.4\%) have voluntarily presented themselves for cervical cancer screening while $259(73.6 \%)$ have not. It was concluded from the study that there was no significant relationship between profession and the attitude of healthcare workers. [21]

\subsection{Factors Affecting Utilisation of Cervical Cancer Screening Services Among Ekiti Nurses}

Factors deduced from the key informant interview to affect utilization of cervical cancer screening include lack of time, fear of lack of privacy and confidentiality, fear of discomfort or pain during the procedure, fear of positive result, inaccessibility of the cervical screening services facility, cost of the screening, inadequate information about cervical cancer screening center, fear of unsafe and infected procedure, fear and beliefs of adverse effect of pap smear, distance of working unit from screening center location and spiritual assurance that I can never be a victim of cervical cancer which agrees with the factors highlighted in study of Sachan, Singh, Patel, \& Sachan; Nwobodo, \& Malami; Ifemelumma, Anikwe, Okorochukwu, Onu, Obuna, Ejikeme, \& Ezeonu. [17, 18, 19] Recommendations from the nurses interviewed include continuous education/awareness program on the benefit of cervical screening for the nurses, 
subsidizing the cost of the screening, increase awareness about the screening and available centers, policy that favours nurses, e.g. making the procedure to be weekends so that those who are on week day duty can do it on weekends and making it a must before picking up a job in government establishment, only female health care workers should be allowed to do the procedure since is a feminine illness etc.

\section{Conclusion}

This study concludes that there is satisfactory knowledge and positive attitude among female nurses in Ekiti State about cervical cancer and screening services, but uptake of screening services for cervical cancer is very low. Knowledge is very important but not usually sufficient in changing individual practices. Motivation usually comes from sources other than factual knowledge about something. Almost half of the nurses $40.8 \%$ have inadequate knowledge about cervical cancer screening services. This group has to be given adequate training as they are the ones who go to the field for outreach activities, maintain a close relationship with the public and play a very important role in educating and motivating the females to undergo cervical cancer screening. Hence, this group has to be given high focus.

\section{Recommendation}

1) Government policy should be directed to compulsory screening as perquisite for employment like other screening.

2) Screening and vaccine should be made available and affordable not only to the nurses but everybody.

3) Government should subsidize the cost of cervical cancer screening and vaccine or completely make them free for everybody.

4) Further research is recommended in aspect of comparison of the utilization and attitude among health care worker on cervical cancer screening service especially in Ekiti state and also emphasizes on the need for addressing the misconceptions and incorrect practices on cancer screening

\section{References}

[1] International Agency for Research on Cancer. Handbooks of Cancer Prevention. Vol 10: Cervix cancer screening. http://www.iarc.fr/en/publications/pdfsonline/prev/handbook10/index. php.

[2] Bray, F., Ferlay, J., Soerjomataram, I., Siegel, R. L., Torre, L. A., \& Jemal, A., (2018). Estimates of incidence and mortality worldwide for 36 cancers in 185 countries. Cancer Journal Clin, in press. http:/gco.iarc.fr/, as part of IARC's Global Cancer Observatory.

[3] Mihret G., Nigus, G. A., \& Semarya B., 2014. "Factors Affecting the Practices of Cervical Cancer Screening among Female Nurses at Public Health Institutions in Mekelle Town, Northern Ethiopia: A Cross-Sectional Study," Journal of
Cancer Research, vol. 2016, Article ID 4743075, 7 pages, 2016. doi: 10.1155/2016/4743075.

[4] Ndejjo, R., Mukama, T., Musabyimana, A., \& Musoke, D. (2016). Uptake of Cervical Cancer Screening and Associated Factors among Women in Rural Uganda: A Cross Sectional Study. PLoS ONE, $11 \quad$ (2), e0149696. http://doi.org/10.1371/journal.pone.0149696

[5] Bruni L, Albero G, Serrano B, Mena M, Gómez D, Muñoz J, Bosch FX, de Sanjosé S., 2019 Information Centre on HPV and Cancer (HPV Information Centre). Human Papillomavirus and Related Diseases in Nigeria., Summary Report.

[6] Ojo, J. O., Adeola, M. O., Awe, O. O., Oluwasina, Y. T., Akinyemi, O. A., Omotoso, P. A., Alatise, O. I., \& Olasode, B J., (2016). Analyses and Distribution of Various Types of Cancers Recorded In Ife-Ijesha Cancer Registry in the Five Year Period 2010 -2014 Ife Journal of Science (2016) vol. 18, no. 4.

[7] Babatunde, O. E., Elegbede, L. M., Ayodele, S. D., \& Abidoye (2013). Prevalence and outcome of Cancers in Ekiti state, southwest Nigeria, Journal of Clinical Oncology, 31 suppl; abstr e 12553.

[8] Sachan, P. L., Singh, M., Patel, M. L., \& Sachan, R. (2018). A Study on Cervical Cancer Screening Using Pap Smear Test and Clinical Correlation. Asia-Pacific journal of oncology $\begin{array}{llll}\text { nursing, } & 5 & \text { (3), } & \text { 337-341. }\end{array}$ https://doi.org/10.4103/apjon.apjon_15_18

[9] Brunner, L. S., Suddarth, D. S., Smeltzer, S. C. O., \& Bare, B. G. (2014). Brunner \& Suddarth's textbook of medical-surgical nursing (12th ed.). Philadelphia: Lippincott Williams \& Wilkins.

[10] Landy, R., Pesola, F., Castañón, A., \& Sasieni, P., (2016). Impact of cervical screening on cervical cancer mortality: estimation using stage-specific results from a nested casecontrol study. British Journal of Cancer, 115 (9), 1140-1146.

[11] Arulogun, O. S., \& Maxwell, O. O., (2012). Perception and utilization of cervical cancer screening services among female nurses in University College Hospital, Ibadan, Nigeria. The Pan African Medical Journal, 11, 69.

[12] Bakari, M., Takai, I. U., Bukar, M., (2015). Awareness and utilization of Papanicoloau smear among health care workers in Maiduguri, Nigeria. Niger J Basic Clinical Science; 12: 34-8.

[13] Olusegun, G., 2015. Awareness and Practice of Cervical Cancer Screening among Women Accessing Care in a Rural Tertiary Hospital in Nigeria, Clinical Medicine Research, 4. 120. 10.11648/j.cmr.20150404.16.

[14] Ugwu, E. O., Iferikigwe, E. S., Okeke, T. C., Ugwu, A. O., Okezie, O. A, \& Agu P. U. 2011. Pattern of gynaecological cancers in University of Nigeria Teaching Hospital, Enugu, South Eastern Nigeria. Niger J Med. 20 (2): 266-9.

[15] Awodele, O., Adeyomoye, A. A., Awodele, D. F., Fayankinnu, V. B., \& Dolapo, D. C., (2011). Cancer distribution pattern in south-western Nigeria. Tanzan J Health Res. 13 (2): 125-31.

[16] Aweke, Y. H., Ayanto, S. Y., Ersado, T. L., (2017). Knowledge, attitude and practice for cervical cancer prevention and control among women of childbearing age in Hossana Town, Hadiya zone, Southern Ethiopia: Communitybased crosssectional study. PLoS ONE 12 (7): e0181415. https://doi.org/10.1371/journal.pone.0181415 
[17] Ifemelumma, C. C., Anikwe, C. C., Okorochukwu, B. C., Onu, F. A., Obuna, J. A., Ejikeme, B. N., \& Ezeonu, O. P. (2019). Cervical Cancer Screening: Assessment of Perception and Utilization of Services among Health Workers in Low Resource Setting. International journal of reproductive medicine, 2019, 6505482. https://doi.org/10.1155/2019/6505482

[18] Yörük, Selda, Açıkgöz, Ayla, Türkmen, Hülya, \& Ergör, Gül. (2019). Risk factors and relationship between screening periodicity and risk of cervical cancer among nurses and midwives. A cross-sectional study. Sao Paulo Medical Journal, 137 (2), 119-125. https://doi.org/10.1590/15163180.2018 .0244230119
[19] Nwobodo, E. I., \& Malami S. A., 2005. Knowledge and practice of cervical cancer screening among female health workers in Sokoto, North Western Nigeria. Med J. 12: 255-7.

[20] Fasanu, A. O., Akindele, R. A., Adebimpe, W. A., Ala, O. A., Omopariola, S. O., \& Adisa, O. P., 2016 international Journal of Medicine and Medical Sciences ISSN: 2167-0404 Vol. 4 (5), pp. 172-177.

[21] Ehiemere, I. O., Maureen, D. F., \& Robinson-Bassey, G. C., (2013). Attitude and practice of cervical cancer screeningamong female health workers in university of Port Harcourt teaching hospital, Rivers State. Journal of Research in Nursing and Midwifery. 4 (4); 072-082. 